\title{
The effects of task instructions and instructed or uninstructed CS on the eyelid response
}

\begin{abstract}
Eyelid responses were conditioned to an instructed and uninstructed CS and with one of three sets on instructions about a sound intensity judgement task accompanying the eyeblink. During acquisition Ss made significantly fewer responses to the uninstructed CS but significantly more responses during extinction. In neither acquisition nor extinction did the sound judgement task effect performance.

\section{Problem}

Spence and his co-workers $(1963,1964)$, employing a number of techniques to increase resistance to extinction of the eyeblink, have interpreted their results via a modified discrimination hypothesis, emphasizing the role of Ss self-instructed set as a response to the discriminable change in stimulus condition from acquisition to extinction. The present study, extending the results of Porter, Engel, Brady, \& Kropp (1964), evaluated the effects of the sound intensity judging task and the type of instructions on conditioned blink rates during acquisition and extinction. In addition, conditioning and extinction were masked on $50 \%$ of the trials by employing a difficult to detect uninstructed $\mathrm{CS}$, and a conventional CS on all other trials.
\end{abstract}

\section{Method}

Seventy-two introductory psychology students, randomly assigned to one of three groups, served as Ss. Two of the three groups, $\mathrm{AC}$ and $\mathrm{BC}$, reported changes in the intensity of a tone presented during conditioning and extinction. Group AC was instructed to attend to the eyelid CS, and that the tone judgements were intended only to distract them. Group $\mathrm{BC}$ received the converse instructions. Group $\mathrm{RC}$ received a tone of constant intensity and was told that it served as a masking noise. All Ss received 50\% of their trials to the instructed CS, the other $50 \%$ of their trials to a barely perceptible dimming of the room light, the uninstructed CS, and were told that the puff would sometimes occur alone.

All Ss were seated in a $5 \times 7 \times 8 \mathrm{ft}$ sound-shielded room, and were asked to fixate on a small neon bulb, $3 \mathrm{ft}$ from $\mathrm{S}$ located behind a 2 in diameter groundglass disc. The onset of four additional neon lamps behind the disc served as the instructed CS. The equipment for presenting the UCS and recording the CR was described previously (Porter et al, 1964). The tone used was a $1000 \mathrm{cps}$ sine wave, averaging $65 \mathrm{db}$ $(+10 \mathrm{db})$. The tone was attenuated by Hewlett-Packard $350 \mathrm{D}$ audio-attenuator.
Other than giving the appropriate tone instructions, Ss were told to relax, watch the disc, and not attempt to control the responses of their eye. Before conditioning started, all Ss received four trials, two to each CS, followed by one trial to the UCS alone. Immediately thereafter, all Ss received 120 acquisition trials and 40 extinction trials, with an average ITI of 16 sec. $(12-16-20 \mathrm{sec}$.$) . Five trials were given to$ the instructed $\mathrm{CS}$, and five to the uninstructed CS, within any one block of 10 trials. During acquisition the CS duration was $550 \mathrm{msec}$. and $2550 \mathrm{msec}$. during extinction. On all trials the UCS, a 3 psi air puff, was delivered during the last $50 \mathrm{msec}$. of CS duration. For all groups the tone was presented continuously during acquisition and extinction.

\section{Results and Diseussion}

Markedly fewer CRs were made to the uninstructed CS than to the instructed CS during acquisition; however, during extinction both CS conditions yielded approximately the same number of CRs. A mixed analysis of variance (Winer, 1962, p. 319) of the number of CRs made over blocks of 10 acquisition trials to each CS, confirmed that Ss made significantly fewer CRs to the uninstructed CS; $F(1,69)=152.4, p<.001$. While the percentage CRs increased rapidly over trials, $F(5,345)=90.2, p<.001$, the difference in number of CRs between groups $\mathrm{BC}, \mathrm{AC}$, and $\mathrm{RC}$ was not significant; $F(2,69)=2.10 ; p>.10$, nor were any of the interactions significant.

Turning to extinction, CRs to the instructed and uninstructed CS occurred with approximately equal frequency. In order to compensate for the different numbers of CRs at the termination of acquisition, Anderson's (1963) shape function method was used for analysis. The index of performance used was: Extinction Performance $=(\mathrm{R}$ ext. $-\mathrm{Rn} / \mathrm{N}) /(\mathrm{R}$ ext. $-\mathrm{R}$ acq. $)$, where $R$ ext. $=10 \%$, and $R$ acq. was the mean percentage CRs in $\mathrm{N}$ extinction trials. Using this index, responses to the uninstructed CS were significantly more resistant to extinction after five trials to each CS, $F(1,69)=4.81$, $\mathrm{p}<.05$; after 10 trials to each CS, $\mathrm{F}(1,69)=4.99, \mathrm{p}<.05$; but not after 20 trials to each CS. All of these analyses began with the second trial of extinction in order to measure extinction performance after $\mathrm{S}$ had already received one non-reinforced trial.

In order to determine the extent of the differences in the distribution of responses, the number and latency of conditioned (C) and voluntary (V) responses for 


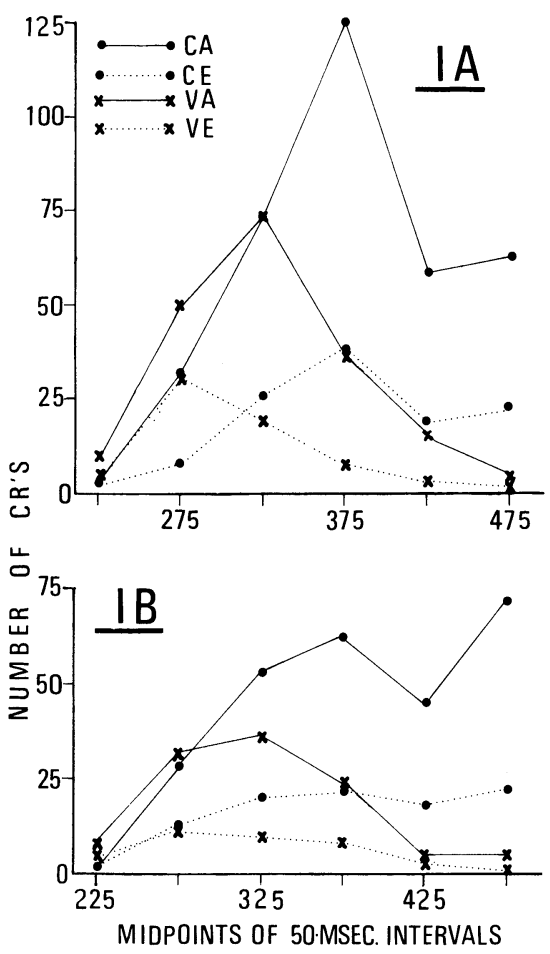

Fig. 1. Mean number of conditioned responses per $50 \mathrm{msec}$. interval following CS onset. Conditioned responses are plotted during acquisition (CA) and extinction (CE), as are voluntary responses (VA, VE). Figure $1 A$ is a plot of responding to the instructed $\mathrm{CS}_{\text {; }}$ Fig. $1 \mathrm{~B}$ is a plot of responding to the uninstructed $\mathrm{CS}$.

groups $\mathrm{AC}, \mathrm{BC}$, and $\mathrm{RC}$, were examined. Placement in the $\mathrm{V}$ or $\mathrm{C}$ categories was according to the criteria used by Spence and Ross (1959). Figure 1 shows CRs as a function of response latency over trials 101-120 of acquisition and trials 1-10 of extinction for all groups.

The CA curves of Figs. IA and $1 \mathrm{~B}$ indicate that the superior response rate to the instructed CS was due primarily to the peak in responding in the $350-400$ msec. range. Otherwise there was little difference in the frequency of CRs to the instructed and uninstructed CS. The VA curves of Figs. $1 \mathrm{~A}$ and 1B, clearly show twice the number of $\mathrm{V}$ responses to the instructed CS as to the uninstructed CS (187 vs. 107), and were similar in latency distributions to those of Goodrich (1964) and Hartman \& Ross (1961), but showed a more precipitous drop in number of $\mathrm{V}$ responses in the 400$500 \mathrm{msec}$. range. The difference in the $\mathrm{CE}$ curvex of Figs. 1A and 1B again reflected the peak in $\mathrm{C}$ responses in the 350-400 msec. range to the instructed CS, while the $\mathrm{VE}$ curves indicated that long latency $\mathrm{V}$ responses extinguished most rapidly. However, the ratio of $\mathrm{C}$ to $\mathrm{V}$ responses remained relatively constant from acquisition to extinction for the instructed CS $(66 \%-34 \%$ in acquisition, $64 \%-36 \%$ in extinction), and for the uninstructed CS $(72 \%-28 \%$ in acquisition, $75 \%-25 \%$ in extinction).

At the end of an experimental session only $19 \%$ of the Ss reported the uninstructed CS; thus it was concluded that the slower rate of extinction to this CS was partially due to Ss being less aware of this phase of conditioning, and thus unable to distinguish the change from conditioning to extinction. This interpretation was in line with that offered by Spence et al $(1963,1964)$.

Before accepting the above interpretation of the rapid extinction of the eyelid $C R$, the implications of the set concept should be examined carefully. If the inhibitory or facilitory functions of set act most readily on responses that $\mathrm{S}$ controls, then $\mathrm{V}$ responses should be facilitated or inhibited to the CS. It follows that a strong inhibitory set at the beginning of extinction should lead to the rapid extinction of $\mathrm{V}$ responses, more rapid than extinction of the involuntary CRs. The present study yielded no evidence of a decrease in the proportion of $\mathrm{V}$ responses for any group. Further, the results of Spence et al (1964), fail to support this interpretation of extinction. While it is clear that other interpretations of set are possible, a more precise definition of the variables governing set is needed before the concept can have significant explanatory value.

\section{References}

Anderson, N. H. Comparison of different populations: Resistance to extinction and transfer. Psychol. Rev., 1963, 70, 162-179.

Goodrich, K. P. Effect of a ready signal on the latency of voluntary responses in eyelid conditioning. J. exp. Psychol., 1964, 67, 496-498.

Hartman, T. F., \& Ross, L. E. An alternative criterion for the elimination of "voluntary" responses in eyelid conditioning. J. exp. Psychol., 1961, 61, 334-338.

Porter, J. J., Engel, R. G., Brady, K. R., \& Kropp, J. H. CS duration and task instructions as determiners of extinction of the conditioned eyelid response. Psychon. Sci., 1964, 1, 375-376.

Spence, K. W., Homzie, M. J., \& Rutledge, E. F. Extinction of the human eyelid $\mathrm{CR}$ as a function of the discriminability of the change from acquisition to extinction. J. exp. Psychol., 1964, $67,545-552$.

Spence, K. W., \& Ross, L. E. A methodological study of the form and latency of eyelid responses in conditioning. J. exp. Psychol., 1959, 58, 376-381.

Spence, K. W., Rutledge, E. F., \& Talbott, J. Effect of number of acquisition trials and the presence or absence of the UCS on extinction of the eyelid CR. J. exp. Psychol., 1963, 66, 286-291. 